DOI: 10.20472/IAC.2018.035.008

\title{
DJULA BOROZAN
}

Faculty of Economics in Osijek, Josip Juraj Strossmayer University of Osijek, Croatia

\section{ESTIMATING THE EFFECT OF THE GREAT RECESSION ON FINAL ENERGY CONSUMPTION}

\begin{abstract}
:
Evolution of total final energy consumption in the European Union (EU) exhibits a mild decreasing tendency over the last two decades. Though, it has recently become more volatile due to the economic recession that adversely and unevenly hit energy consumption in most EU countries and their energy end-use sectors.

Eurostat's data unveils the considerable differences that exist in finale energy consumption across the "old" and post-transition EU countries as well as the major energy end-user sectors. Using random effects panel model, this paper aims to estimate the effect of the Great Recession and the membership status ("old" vs. post-transition groups) on final energy consumption in the major energy end-user sectors for the period 1998 - 2015.

The empirical evidence indicates statistically significant impact of both predictors on final energy consumption of households/services and industry. However, the impact is not uniform which raises several important questions regarding their behavior and reaction to the recession. Since the recession reduced the wealth and income of the European households, it seems that they are not prone to invest in more energy-efficient appliances, technologies and innovations in tough economic times. In contrast, such behavior is a precondition for survival and future growth of industry.
\end{abstract}

\section{Keywords:}

Great Recession, final energy consumption, energy end-user sectors, random effects panel analysis

JEL Classification: C33, E32, Q43 